\title{
Irrepressible Images: New Films in China from 1995
}

Jia Zhangke

\section{OpenEdition}

\section{Journals}

Electronic version

URL: http://journals.openedition.org/chinaperspectives/5056

DOI: 10.4000/chinaperspectives.5056

ISSN: 1996-4617

Publisher

Centre d'étude français sur la Chine contemporaine

\section{Printed version}

Date of publication: 21 April 2010

ISSN: 2070-3449

\section{Electronic reference}

Jia Zhangke, «Irrepressible Images: New Films in China from 1995 », China Perspectives [Online],

2010/1 | 2010, Online since 01 April 2013, connection on 28 October 2019. URL : http://

journals.openedition.org/chinaperspectives/5056 ; DOI : 10.4000/chinaperspectives.5056

(c) All rights reserved 


\title{
Irrepressible Images
}

\section{New Films in China from 1995}

\author{
川A ZHANGKE
}

Jia Zhangke, who had long accompanied his activities as a film-maker with theoretical reflections in the form of short articles, recently published a collection of his selected writings entitled Jia Xiang. Jia Zhangke dianying shouji 19962008. Pai dianying shi wo jiejin ziyou de fangshi, Beijing, Peking University Press, 2009 (Jia's thoughts. Jia

Zhangke's film notes 1996-2008. Making films is my way of approaching freedom). Bringing together many important texts, this publication marks a retrospective moment in his work. Three essays have been selected for translation in this issue: "Irrepressible Images," written in 2002, but which is also a reworking of two seminal essays published in 1998, "The Age of amateur cinema is about to return" and "Now that we have VCDs and digital video cameras." The article sets out Jia Zhangke's view of how independent film in China developed since the early 1990s. It is followed by one essay on Jia's documentary In Public, dealing more specifically with space as an inspiration for film. Also in 2009, to accompany his latest film, 24 City, Jia published a collection of the interviews on which the film is based, entitled: Zhongguo gongren fangtan lu. Ershisi cheng ji (Interviews with Chinese workers. 24 City). A Collective memory of Chinese Working class, Jinan, Shandong huabao chubanshe. The preface to this collection is also included in this issue. (SV)

$\mathrm{O}$ ne day in 2001, the Beijing Evening News published the following item: a seller of pirated DVDs was arrested in the office of the literature department of the Beijing Film Academy. This person came to the Academy regularly to sell DVDs to teachers and students, and was denounced by some students with strong feelings about intellectual property rights. The literature department was also drawn into the matter because it had offered him a place to sell his DVDs. The unofficial version of the story was even more colourful: the seller had not been denounced by a student, but by a colleague engaged in the same pirate trade. This sounded like the plot of a gangster film, and what made it even more absurd was that it had happened at the famous Beijing Film Academy. At most, the offender could be called a retailer, but as the story of his fortune was told by the students, it sounded more like the plot of an "ambitious youth" [qingchun lizhi] film. In 1999, when DVDs were just becoming common in China, this man, who had come to Beijing from the provinces, would trek to the Film Academy every day with a satchel of DVDs to ply his trade. After half a year, he bought a motorcycle, which allowed him to shuttle between Beijing's many universities. In 2000 he exchanged it for a second-hand jeep, and at the time of his arrest, people noticed that he had just bought a brand new Santana limousine.

From an economic and legal viewpoint, this story of course shows that China still has a serious problem with intellectual property rights, but from a cultural viewpoint, it is more important to understand that China has a huge demand for films. Although around 250 official films were shot every year at the peak of production, works originating from other cultures, those classics of cinema that had influenced and moved humanity, were forever beyond our grasp. Before pirated DVDs began circulating, it was hard to imagine that an ordinary city dweller could see films such as Godard's Breathless or Tarkovsky's The Mirror. Even popular American films such as The Godfather or Taxi Driver were hard to find. People were quite unfamiliar with films, and had no way of sharing the cultural experience built up by humanity through cinema over the course of a century.

It is easy to understand the lack of images in China before the "reform and opening up" policy was implemented in 1979. Even people with a rudimentary understanding of China know that this episode of Chinese culture was encased in extreme prohibition. Apart from so-called revolutionary art, there was not the slightest loophole for any other form of culture. But to understand what happened after the end of the "Cultural Revolution," especially the limitations film was subjected to in China in the 1980s, it is necessary to make some detours. As we all know, following the thaw in national politics, a wave of thought freedom gradually began to rise. A large amount of modern Western literature, music, and art began to be translated and introduced to China. Around 1989, there even developed a nation-wide 


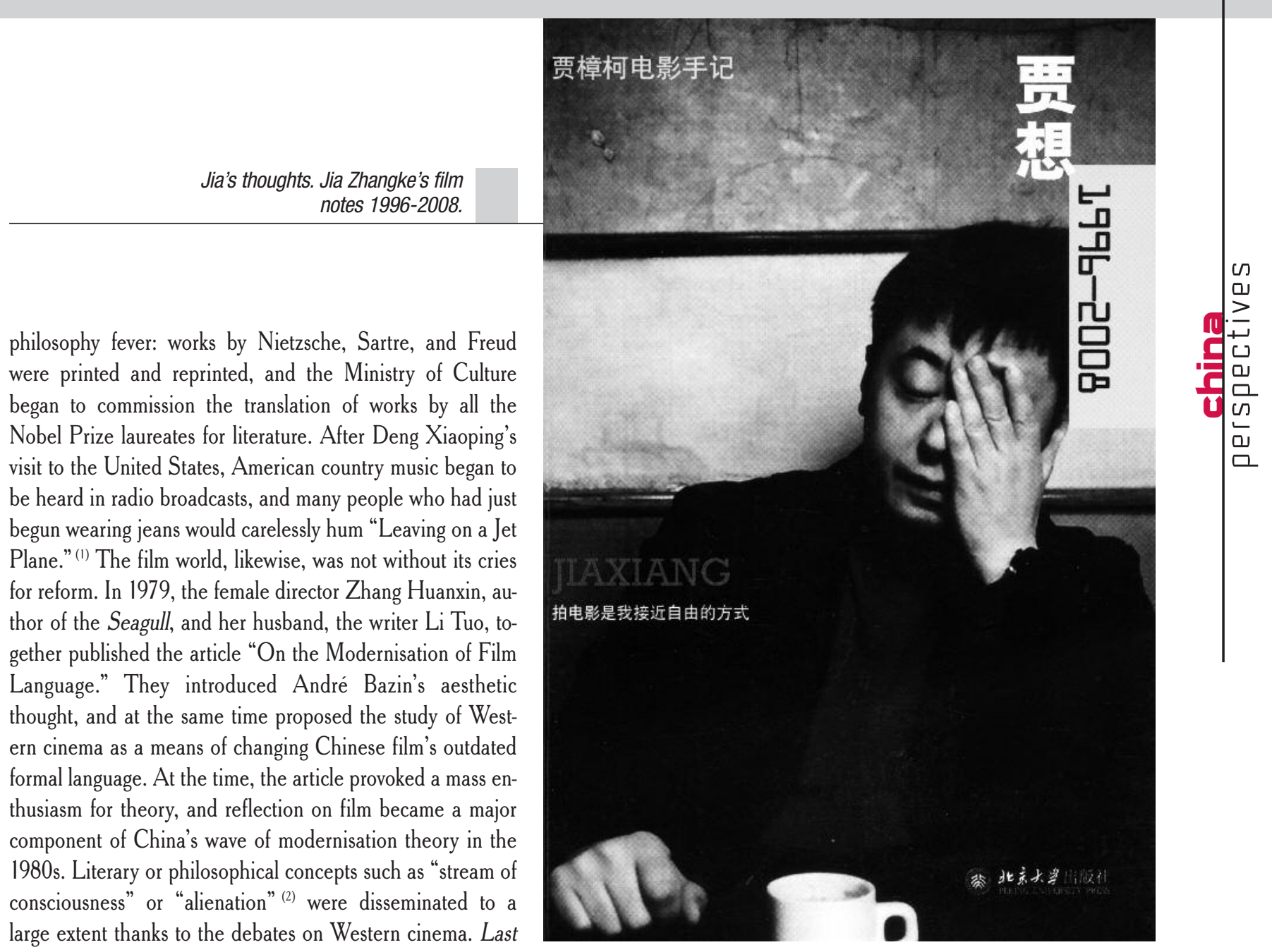
Year in Marienbad by Alain Resnais and The Red Desert by Antonioni became introductory courses to modern Western art for Chinese intellectuals, and words such as "Godard," "jump cut," "Left Bank," and "Fassbinder" appeared more and more often in their articles.

This was probably a first step, which allowed films such as The Four Hundred Blows or The Nights of Cabiria to freely enter the intellectual life of Chinese people in the same way as works of literary fiction such as One Hundred Years of Solitude or Metamorphosis. Contrary to expectations, the cultural authorities, faced with this wave of intellectual liberation sweeping through society, continued to firmly implement strict control on films coming in from abroad. Only a tiny number of professional film workers and elite intellectuals were allowed to see these films at restricted screenings closed to the general public, which were called "internal screenings," and the films were labelled "internal reference films." During the long period of the "Cultural Revolution," only Beijing opera films of the eight "model operas" were authorised for screening, all of them telling heroic stories of the Party and the Army meant to educate the 800 million Chinese. The name "internal reference film" gave these screenings a strong academic or professional flavour, while also providing an explanation to the public by stating that these films could only be viewed "internally." When the public's and especially the intellectuals' huge demand for films at the beginning of the 1980s put pressure on the cultural authorities, they tried to miti-

gate it by extending the screenings of "internal reference films," on the one hand enlarging the circle of those with privileged access, while on the other hand tightly controlling the public by once again placing the showings within strict limits.

In this way, the privilege of viewing "internal reference films" was extended from fewer than 1,000 officials and political stars to the stratum of elite intellectuals. Cultural work units in Beijing and Shanghai received permission to organise occasional "internal screenings" with the aim of satisfying the academic needs of a group of professionals. Tickets were distributed - there was no need to pay. The only problem was that, although the group of privileged people had been extended, the privilege was unchanged. For example, cities outside Beijing and Shanghai were largely unable to organise similar screenings for intellectuals, and apart from a small number of so-called "professionals," ordinary citizens were always turned away at the theatre doors. But the exciting atmosphere of the screenings still managed to spread outside the theatres; intellectuals delighted in discussing The Deer Hunter or Kramer vs. Kramer, and the names of Meryl Streep and Dustin Hoffman began to reach Chinese

1. Written by John Denver in 1967; Denver toured China in 1992. (All notes by the translator)

2. In the context Jia is discussing, this term probably refers to both the debate on "alienation in socialism," which took place in the 1980s, and Brecht's Verfremdung or "defamiliarisation". 
ears. ${ }^{(3)}$ This spread a thin veneer of culture over society while allowing the true situation to remain hidden.

This raises the question of why a relatively liberal policy was adopted towards literature and music, while film was singled out for tight control. Lenin had said: among all the arts, cinema is the most important for us. It was seen as endowed with a greater capacity to influence because of its ability to overcome the obstacle of language; even the illiterate can understand new ideas through images. That is why beginning in the 1980s, people were free to buy Proust's Remembrance of Things Past in a book store, but were not allowed to attend public screenings of any of Godard's films. Firmly believing in Lenin's teachings, cultural officials banned images. Even in today's China, cultural policy is by no means as free as economic policy, and film has the misfortune of being the most conservative link in the cultural chain.

The situation only began to change slowly after 1995, but no one imagined that what would break up the control over film would be those pirate VCDs from the coastal areas of Guangdong and Fujian. The coastal fishermen in their wooden boats had early on supplied their compatriots with Sony tape-recorders and pop music from Hong Kong and Taiwan; now, 15 years later, they used the same method to secretly import films from Hong Kong and Taiwan. Before VCDs became widespread, the expense of home video recorders and VHS tapes made home viewing of films a luxury. But in 1995, more than a dozen factories producing VCD players sprang up in southern cities, and their fierce competition rapidly brought the price of VCD players down from over 3,000 yuan to around 800 yuan. Most urban residents were now able to buy this kind of electronic product, and installing a "home cinema" soon became the fashion. One television set and one VCD player, one amplifier and two speakers were sufficient for a simple system that allowed a middle school teacher or a taxi driver to organise private screenings at home. This was also the time when computers were entering people's lives, and installing a CDRom drive on one's PC became extremely fashionable.

At the beginning, the films smuggled back on fishing boats from Taiwan and Hong Kong were a startlingly abundant but haphazard mix: a stack of Hong Kong martial arts films from the 1970s might also contain a copy of Citizen Kane or Battleship Potemkin. But they were still mostly commercial Hong Kong films: John Woo's masterpieces A Better Tomorrow and The Killer, Tsui Hark's Once Upon a Time in China, and Jackie Chan's kung-fu comedies were all received with enthusiasm. The wave of American films arrived soon afterwards, and pirates followed the newest trends in

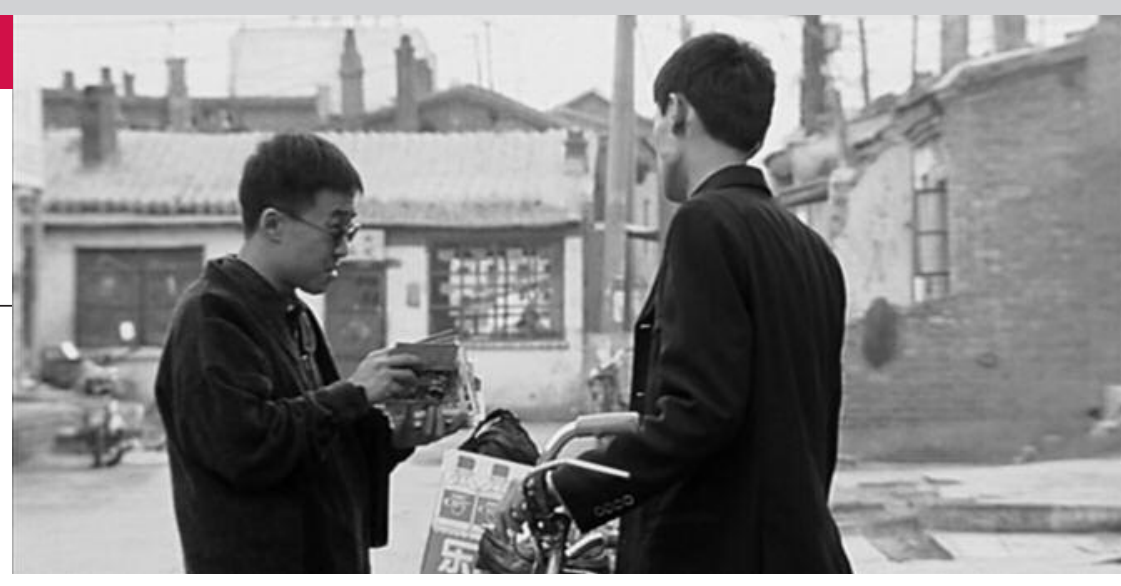

Hollywood while at the same time organising a complete retrospective of American film for their customers. For example, when True Lies was released in the United States, a pirated version was available in Beijing one week later. These VCDs distributed almost simultaneously with Hollywood were invariably "gunpoint versions," shot in theatres with a handheld camera facing the screen and immediately copied. In these versions you could often hear the audience laughing or coughing, and sometimes an audience member leaving in the middle of the film would even flash across the picture. Films such as The Godfather, Taxi Driver, and The Graduate were pirated one after the other, and people began to pay attention to the tastes of intellectuals; this is when small shops specialising in European films began to appear on the streets. To the great displeasure of MK2, one of the first of these pirated films was Kieslowski's Three Colours: Blue, but Juliette Binoche gained a million fans.

To a vast majority of the Chinese audience, even a film shot in 1910 was new. The films of legend, the directors known by only a few words and phrases, the actors known only from film posters, suddenly descended among the ordinary people, engendering an irrepressible enthusiasm. Official control over films was effectively reduced to control over the legal sale of films. The Film Bureau had resorted to diplomatic channels to express its deep discontent over Richard Gere's role in Red Corner, but the pirated VCD of this film could be viewed throughout Beijing. Sellers of pirated copies established a network covering all of China's urban and rural areas, and it is probably no exaggeration to say that wherever there was a post-office and a gas station, there would be a local retailer of pirated VCDs. For Chinese people who had been isolated from pictures, pirated discs provided the right to freely contemplate images. That is why overcoming an unreasonable policy of isolation from films by engaging in illegal pirating entraps us in an unseemly paradox. Most consumers of pirated films believe that the act of pirating is immoral, but nobody believes that buying a pirated disc is wrong. People were caught up in the double euphoria brought on by the restoration of rights and the appearance of pirate films. In 1999, similarly cheap domesticmade DVD players flooded the market, and people began

3. The Deer Hunter (1978), by Michael Cimino, starring Meryl Streep, and Kramer vs Kramer (1978), by Robert Benton, starring Dustin Hoffman and Meryl Streep. 
updating their equipment to watch DVDs with a higher audio-visual quality. As if to match this technical progress, sellers of pirated discs also began to offer better films than in the VCD era. Fellini, Antonioni, Tarkovsky, Godard, Rohmer, Kurosawa, Hou Hsiao-hsien: there seemed to be copies of all the most important films in the history of cinema.

In 1997, the first unofficial film group, "Office 101" (101 bangongshi), was established in Shanghai, demonstrating that young people were no longer satisfied with private screenings and yearned to establish a platform for free expression and exchange. "Office 101" had about 200 fixed members, among them teachers, workers, office employees, and students. The initiator, $\mathrm{Xu}$ Yuanyuan, was employed by the Shanghai Customs Office, but resigned upon founding the group. They chose the Hongkou Cultural Hall as their venue for regular screenings, after which they organised collective discussions, the content of which was published in their unofficial journal, which they printed themselves. After 1999, film clubs like this one appeared in great numbers. In Guangzhou there was the Southern Film Forum (Nanfang dianying luntan), organised around a group of journalists and people working in the audio-visual media; in Nanjing there was Back Window Films (Houchuang kan dianying), Wuhan had Wuhan Film Watchers (Wuhan guan ying), Jinan had Ordinary People's Film (Pinmin dianying), Beijing had the Practice Society (Shijian she) and Phenomenon Studio (Xianxiang gongzuo shi), Shenyang had Free Film (Ziyou dianying), Changchun had its Changchun Film Study Small Group (Changchun dianying xuexi xiaozu). If you were to leaf through an atlas of China, you would find that cities with film groups extended all over the Chinese mainland.

Even more surprising was that, not long after having been established, most of these groups extended their activities to an even more public level. In Beijing, the Practice Society used the Box Bar (Hezi) near Tsinghua University as a screening venue, and regularly organised specialised screenings such as Fellini or Bunuel retrospectives. At the outset only members were internally informed of the organised activities, but very soon information on the screenings appeared in the pages of Beijing Youth Weekly (Beijing qingnian zhoukan), Guide to Quality Shopping (Jingpin gouwu zhinan), and other popular magazines. Soon after, almost all the groups seemed to have their own BBS on the Internet, seeking a breakthrough for their discursive space. The most famous film discussion forum was the Nanjing BBS run by Back Window Films, while the Practice Society's Yellow
Pavilion Images Online (Huang tingzi ying xian) also had a large number of hits.

By using www.xici.net, it was easy to find the homepages of all these groups. On their BBSs, the discussion turned from the initial criticism of Western films to reflections on the reality of Chinese cinema. Independent Chinese films that had been shot since the 1990s but had never been publicly released began to draw attention. Zhang Yuan's Sons (Erzi), Wang Xiaoshuai's The Days (Dongchun de rizi), He Jianjun's The Postman (Youchai), Lou Ye's Weekend Lover (Zhoumo qingren): all these films that had lain covered in dust began to appear on the programme lists of all the film groups. And when these previously forbidden images finally reached people's eyes in the noisy environment of a bar, we could only conclude that these were irrepressible images.

Zhang Yuan, Wang Xiaoshuai, and the first cohort of independent Chinese directors began working as figures of rebellion against the system. In 1989, they had just graduated from Beijing Film Academy. After the great social unrest, a number of intellectuals began to adopt a way of life that set them apart from the system. These feelings can be discerned from the anger of Beijing Bastards to the loneliness of The Days. Film no longer followed the production methods associated with the studio system; the feelings they depicted were at odds with the current film system, and inevitably these films were banned by the authorities. However, the independent film movement that originated from this event remained misunderstood by the public for a long time. It was only when film group organisers borrowed VHS tapes from the directors and showed their films in bars that the notion of independent film began to be understood by more and more young people. At this time, more young people from outside the film system were finalising their preparations to shoot independent films. Just as reading can arouse the desire to write, the free viewing that had begun in 1995 instilled in more young people an interest in shooting films. Some of them were students, while others were workers, office employees, writers, or poets: indeed, the technical limitations that their amateur background imposed on them were not that great, because this was already the vibrant era of Digital Video.

The change brought about by DV in China was no less than a change in the cultural habits of an entire people. Before this, the Chinese did not have a tradition of using moving images to express themselves, to the point that few people even took photographs. The reading and writing of literature was the mode of expression we excelled in, while visual ex- 
perience was sorely lacking. After 1949, the government decided that only official film studios would have the right to shoot films, and cinema effectively became an artistic monopoly. We were isolated from film for so long that we forgot that expressing ourselves through film was originally our right. When the Chinese began trying to look at this world through a viewfinder, DV provided them with not only a new mode of expression, but also a restoration of their rights. After 1995, the majority of experimental film directors chose to leave the road of making films within the censorship system. Working in a non-official [minjian] manner and taking an independent stance, Chinese people began creating a brand-new film world outside the system, and attempted to progressively organise their visual life autonomously.

Many directors using hand-held DV cameras chose documentary film as a starting-point for their creative work. This stimulated further enthusiasm, because in the century-long history of Chinese film, two types of tradition had been lacking: documentary film and experimental film. The independent nonofficial visual movement [minjian duli yingxiang yundong] triggered by DV filled this vacuum, while scattering its directors over a much broader area than ever before. In the past, the majority of directors lived in cultural capitals such as Beijing and Shanghai, but now, even places as far away as Sichuan or Guizhou began experiencing waves of film-making. The most famous directors among them were Yang Tianyi, Du Haibin, and Wang Bing in Beijing, Ying Weiwei in Shenyang, Hu Shu in Guizhou, and Wang Fen in Jiangxi. In 1996, Yang Tianyi, who at that time was still employed as an actress of the Drama Troupe of the People's Liberation Army's General Political Department, began to shoot her first documentary Old Men (Lao tou). The shooting came about in a quite fortuitous manner: Yang Tianyi would frequently come across a row of old men basking in the sun in her neighbourhood. She was moved by this scene to begin shooting their lives using her hand-held DV camera. In the following two years, during which she continuously filmed the time of their slow passing, she captured their attachment to and reverence for life, and documented the end of life and their farewell to existence. Du Haibin, a graduate of the Beijing Film Academy's photography department, while returning to his hometown of Baoji, Shaanxi, for the Spring Festival of 2000, met a group of vagabond youths along the railway tracks, and shot Along the Railroad (Tielu yanxian). He drifted along with them, and his camera cut through their miserable appearance and entered the youthful dreams of these adolescents.
Wang Bing's West of the Tracks (Tiexi qu) can be described as a super-production in which the author edited 300 hours of material he had shot over two years to craft a trilogy of independent but spatially-related films. Tiexi is an industrial district in Shenyang where state-owned factories are now faced with bankruptcy, leaving the whole area in hopeless desolation. The real situation of workers appears even grimmer in the icy weather of the Northeast. Areas slated for destruction, such as Yanfen Street, the old men in the workers' sanatorium who use plastic bags to fish for small shrimp, families staring blankly at their television sets, and the old train still speeding through Tiexi District, compose a panorama of the failure of the planned economy.

Female director Ying Weiwei lives in Shenyang; I don't know whether she is familiar with Tiexi District. Her background is in Chinese literature, and her film The Box documents the life of a lesbian couple living together in an apartment unit. During their uninterrupted heart-to-heart talks, they both hurt and show care for each other. The documentary thus began to open up an unfamiliar private space, as if entering a sealed box. Another female director, Wang Fen, turned on her camera in her hometown of Jinxian, Jiangxi Province, in the year 2000, and began filming her parents, documenting family secrets, those endlessly repeated complaints, and inescapable family reproaches. This film, entitled More than One is Unhappy (Bu kuaile buzhi yige), ${ }^{(4)}$ has the strong flavour of a cutting of ties. These two works both have the feel of the Japanese "I-novels" (watakushi shosetsu), demonstrating the continued dilution of ideology.

$\mathrm{Hu}$ Shu works for an official television channel, but he went to Guizhou independently to shoot Leave Me Alone (Wo bu yao ni guan). In Guiyang, he followed the sentimental lives of several "three-service girls" (sanpei xiaojie), ${ }^{(5)}$ observing them fall in love and confront betrayal. Their thirst for love makes their youth in a quiet border town seem excessively melancholic, so that one cannot help thinking of Shen Congwen's light and informal style steeped in the consciousness of being alive, as well as of the Chinese classic Springtime in a Small Town, made in 1947. Interestingly enough, another director, Zhong Hua, two years after leaving the army, thought up a way of returning to the place where his garrison was stationed, and privately shot a documentary about the lives of active servicemen called This

4. This film received the New Wave Prize at the Yamagata Festival in 2001.

5. A common euphemism for prostitution: in theory the three "accompaniments" are chatting, dancing, and drinking with the client. 
Winter (Jin nian dongtian). ${ }^{(6)}$ This phenomenon of directors with strong links to the mainstream system drifting further away from mainstream culture has become very common in recent years. Documentary film has expanded the aesthetic scene of cinema to the entire country, and has turned the hands of cinema's clock back to the present, looking at real life conditions to tell the story of the Chinese people's current experience. Documentary is thus changing the "dramatic tradition" that has always influenced Chinese cinema.

Some of the first to shoot experimental works included Guangzhou Fine Arts Academy graduate $\mathrm{Cao}$ Fei, and Shanghai artist Yang Fudong. Cao Fei's earliest work, Chain (Lian), was strongly reminiscent of Bunuel's $U_{n}$ chien andalou: among the fragments of broken footage you could occasionally see a simulated operation. Machines, organs, and blood from an unknown source, wedding ribbons, and plastic flowers seem to express a feminine anxiety. Yang Fudong's work Hey! Sun is Rising (Hei, tian liang le) reminds the viewer of the uncanny atmosphere in Philip Kuhn's study Soulstealers: The Chinese Sorcery Scare of 1768 , ${ }^{(7)}$ with fleeting spirits wandering along broad southern streets grasping swords, that kind of Chinese-style uneasiness. This year, Yang Fudong presented his new 90minute black-and-white film An Estranged Paradise (Mosheng tiantang) at the Kassel biennale [Dokumenta 11]. In the film, a poet suddenly thinks he has fallen ill, but after all sorts of tests his spirits rise again. At that point, this southern city of Hangzhou, which is sometimes called "Paradise," has also passed through its rainy season of "Plum Rain." There are some other works that can perhaps be more correctly classified as "video art," many of which are exhibited as installations in art museums.

Of course, there are still many people shooting feature films. Nanjing director Zhu Wen was one of the first to shoot feature films using DV. Before that, his novels had already attained a tremendous following among young people. He helped Zhang Yuan complete the script for Seventeen Years (Guo nian huijia), and wrote the script for Clouds over Wushan (Wushan yunyu) for Zhang Ming. In the winter of 2001, he shot the film Seafood (Haixian) in a little over ten days in the northern seaside resort of Beidaihe. It tells the story of a "three-service" girl who wants to commit suicide and a policeman who will not let her die. The policeman uses his power to obtain sex, but the young woman, after ending the policeman's life with a gun, decides to continue living. The word "seafood" has a violent meaning in presentday Chinese: this film is a rough depiction of a rough real- ity. In Shanghai also, people are pursuing independent production: the young director Chen Yusu collaborated with best-selling author Mian Mian to make We are Scared (Women Haipa), describing the lives of young people in this city that has restored the spirit of capitalism.

Last summer, a non-fictional young man from that city came to my office in Beijing. He was a student from Shanghai University who was planning to hold a series of screenings on campus. They wanted to show Xiao $W u$ and asked me for a high-quality video recording. I took a disc out of the closet and gave it to him, and in exchange he took out a contract and asked me if I would agree to sign it. It was a letter of authorisation, stating that the holder of the copyright for Xiao $W u$ in China, Jia Zhangke, agreed to have this film screened within the stated festival. This was the first time I had seen anyone in China who understood how to deal with copyright. I happily signed my name, although it said at the top that the fee they would pay was equal to zero yuan.

China is developing at full speed; everything is moving very fast. For us, the most important thing is to tightly hold on to our camera and tightly hold on to our rights. •

\section{- Translated by Sebastian Veg}

6. This film was awarded the Prix Premier of the International Documentary Film Festival of Marseille in 2002, the year in which Jian Zhangke's In Public received the top prize of the International Competition.

7. Harvard University Press, 1990; published in Chinese translation by Sanlian in 1999. 